\title{
HOT TOPICS AND EMERGING TRENDS IN BUSINESS MODEL INNOVATION RESEARCH BASED ON CITESPACE
}

\author{
Tian Xu \\ Universiti Teknologi Malaysia, Malaysia \\ Hebei Finance University, China \\ Dr. Noraini Bt. Abu Talib \\ Universiti Teknologi Malaysia, Malaysia
}

\begin{abstract}
Business model innovation has become an important way for companies to gain a competitive advantage and has been a hot research topic in the academic field in recent years. A bibliometric analysis, based on 600 articles retrieved from the Web of Science Core Collection database from 2000-2019, was carried out to provide insights into hot topics as well as emerging trends in business model innovation. This article uses bibliometric methods and CiteSpace visualization tools to analyze discipline and institution, time series, keyword co-occurrence, keyword clustering, time line diagram, and time zone diagram. The study shows that the number of literature in the field of business model innovation has an increasing trend year by year, and generally focuses on the topic of value creation, with hot topics such as business model sustainability, servitization, small and medium-sized enterprises, and entrepreneurial model innovation. In terms of research trends, more attention is paid to the way traditional industries achieve sustainable operation and transformation and upgrading through disruptive innovation.
\end{abstract}

Key words: Business model innovation; Bibliometrics; Visualization; Scientific knowledge mapping

Cite this Article: Tian $\mathrm{Xu}$ and Noraini Bt. Abu Talib, Hot Topics and Emerging Trends in Business Model Innovation Research Based on Citespace, International Journal of Management, 11(12), 2020, pp 2200-2210.

http://iaeme.com/Home/issue/IJM?Volume=11\&Issue=12

\section{INTRODUCTION}

Business model innovation, as the sixth source of innovation in addition to Schumpeterian innovation theory, has expanded new ideas for strategic change and upgrading of enterprises. 
With the widespread development of the Internet and e-commerce, more and more companies are relying on their innovative business models to achieve commercial success, making the study of business model innovation a common topic of interest for both business and academics. Such as Gong Limin et al(2010 ${ }^{[1]}$ using UCINET software, analyzed the citation relationship of business model theoretical research literature based on SSCI data citations from 1997 to 2010, and identified three basic research areas: the study of business model concepts and elements, the study of business models in strategic areas, and the study of business models in innovation and entrepreneurship. Based on previous research, this article applies bibliometric methods in an attempt to identify the current research status, hotspots, and trends in the field of business model innovation.

\section{LITERATURE REVIEW}

Based on the review of relevant literature, this article shows four different kinds of the concept of business model innovation.

First of all, from a strategic perspective, Matthyssens et al. (2006) ${ }^{[2]}$ argue that business model innovation is fundamentally a strategy for enterprises to reshape their core competencies and gain and maintain competitive advantages through differentiation. Secondly, business model innovation is a concept of elemental change, and Osterwalder et al. $(2005)^{[3]}$ argue that changes in all the components of a business model may successfully trigger the realization of business model innovation. Foss and Saebi $(2017)^{[4]}$, however, emphasize that business model innovation is a design, novelty, or change in focus of key elements, rather than a change in all the components. Thirdly, business model innovation is one kind of systematic innovation, Zott and Amit $(2010)^{[5]}$ consider it as a change or creation of a new operating model to reset the business system based on the reorganization of internal and external resources and the integration of capabilities. Velu $(2015)^{[6]}$ argues that business model innovation involves systematic changes in the value proposition, value creation, and value capture. Finally, scholars believe business model innovation is about value creation. Dubosson-Torbay et al. (2002) ${ }^{[7]}$ understands the process of business model innovation from the perspective of value creation, which is the process of adding value and extracting new value. Chesbrough $\mathrm{H}(2010)^{[8]}$ considers business model innovation is defined as the search for new business logic and new ways of creating and capturing value for the company's stakeholders.

\section{DATA COLLECTION AND RESEARCH TOOLS}

\subsection{Data Collection}

This article uses the Web of Science(WOS) to search the literature on business model innovation. We use the following criteria to retrieve articles from the WOS Core Collection database. (1) topics= the combination of "business model innovation";(2) index =Science Citation Index Expanded (SCI-EXPANDED), Social Sciences Citation Index (SSCI), Arts \& Humanities Citation Index (A\&HCI), Conference Proceedings Citation Index (CPCI-S, CPCISSH), Book Citation Index(BKCI-S, BKCI-SSH) and Emerging Sources Citation Index (ESCI); (3) time span = "2000-2019"; (4) document types= "article". In all, a total of 601 relevant articles have been found and download on $13^{\text {th }}$ March 2020. After completing the search, the data from the above database sources were weighted, identified, and sorted to remove irrelevant and duplicate articles, getting 600 articles at last.

\subsection{Research Tools}

This article adopts a bibliometric and scientific knowledge mapping to carry on the visual processing of relative literature. Bibliometrics is one kind of scientific method, it can 
statistically analyze a subject based on the literature and the quantitative characteristics associated with the literature. Citespace is one of the most powerful and popular software using for visualizing and analyzing a field's state of research, it can reveal the corresponding topics and the trends of knowledge domains by giving visual scientific knowledge maps for any given field(Chen C 2006) ${ }^{[9]}$. Keywords are a high-level summary of the topic of the article, the application of CiteSpace software can intuitively reflect the theme of the research, keyword clustering is more conducive to the analysis of the current situation, hotspots, and evolution of the research. Therefore, we applied CiteSpace as the visualization and analysis software to analyze WOS literature data in terms of discipline, institution, time series, keyword co-occurrence, keyword clustering, time line, and time zone.

\section{STATISTICS AND ANALYSIS OF BUSINESS MODEL INNOVATION}

\subsection{Discipline Analysis}

Knowing the distribution of disciplines in which the research topic is located provides a better understanding of the scope of the research and is the basis for subsequent keyword analysis. A list of business model innovation research disciplines (Table 1) and their respective discipline distribution pie charts (Figure 1) was obtained by studying the discipline distribution of 600 articles in the field of business model innovation.

Table 1 Research Disciplines (Top 10)

\begin{tabular}{lc}
\hline \multicolumn{1}{c}{ Discipline } & Freq $\cdot$ \\
\hline BUSINESS \& ECONOMICS & 396 \\
MANAGEMENT & 280 \\
BUSINESS & 216 \\
ENVIRONMENTAL SCIENCES \& & 108 \\
ECOLOGY & 103 \\
ENGINEERING & 92 \\
SCIENCE \& TECHNOLOGY - OTHER & 91 \\
TOPICS & 83 \\
ENVIRONMENTAL SCIENCES & 54 \\
GREEN \& SUSTAINABLE SCIENCE \& & 44 \\
TECHNOLOGY & \\
ENVIRONMENTAL STUDIES & \\
ENGINEERING, ENVIRONMENTAL &
\end{tabular}

As shown in Table 1 and Figure 1, the major research disciplines in this field are Business \& Economics, Management, Business, Environmental Sciences \& Ecology, and Engineering, with more than 100 publications, accounting for $27 \%, 19 \%, 15 \%, 7 \%$, and $7 \%$ of the total, respectively. It can be seen that business model innovation research covers a relatively rich range of disciplines, and the important disciplinary areas are prominent, with the top five categories accounting for nearly $80 \%$ of the cumulative value, indicating that the topic has received extensive attention from researchers from multiple disciplines, and the focus is prominent, indicating that the content has important research significance, as well as a typical and clear research scope. 


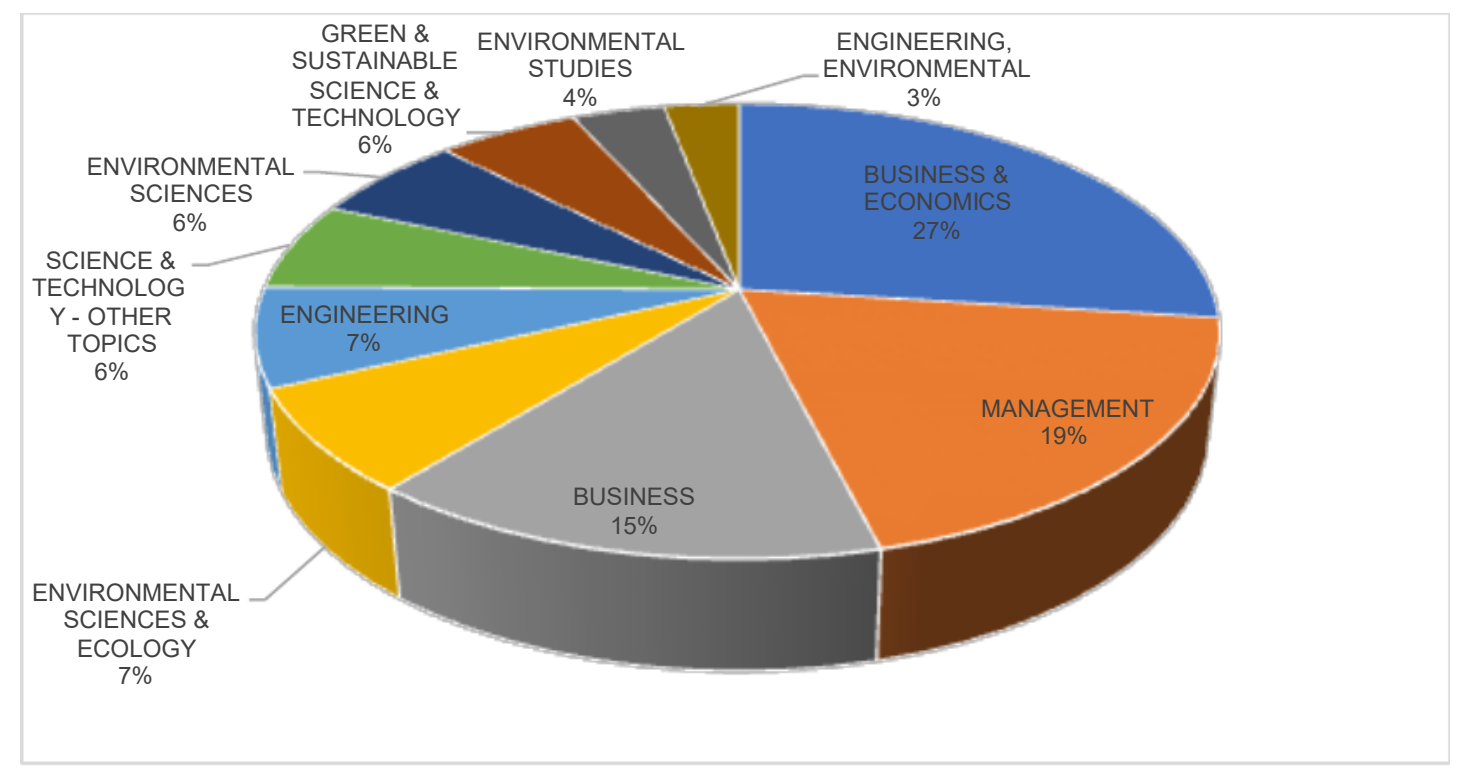

Figure 1 Distribution of Research Disciplines

\subsection{Research Institutions Analysis}

By analyzing the research institutions, it is possible to get a more accurate picture of the main areas of research on business model innovation and to understand the importance that each institution places on the topic. In the theme of business model innovation, research institutions cooperate closely. As shown in Figure 2, forming a network of research institutions based on the University of Cambridge (UK), Delft University of Technology (the Netherlands), Lund University (Sweden), Aarhus University (Denmark), and Linkoping University (Sweden) as their respective cores are relatively typical of the collaborative research results. According to the literature data, the top 10 research institutions in terms of the number of articles published were selected and tabulated, as shown in Figure 3, with the University of Cambridge in the first place and the Delft University of Technology in the second place, both of them published more than 20 articles in the last 20 years.

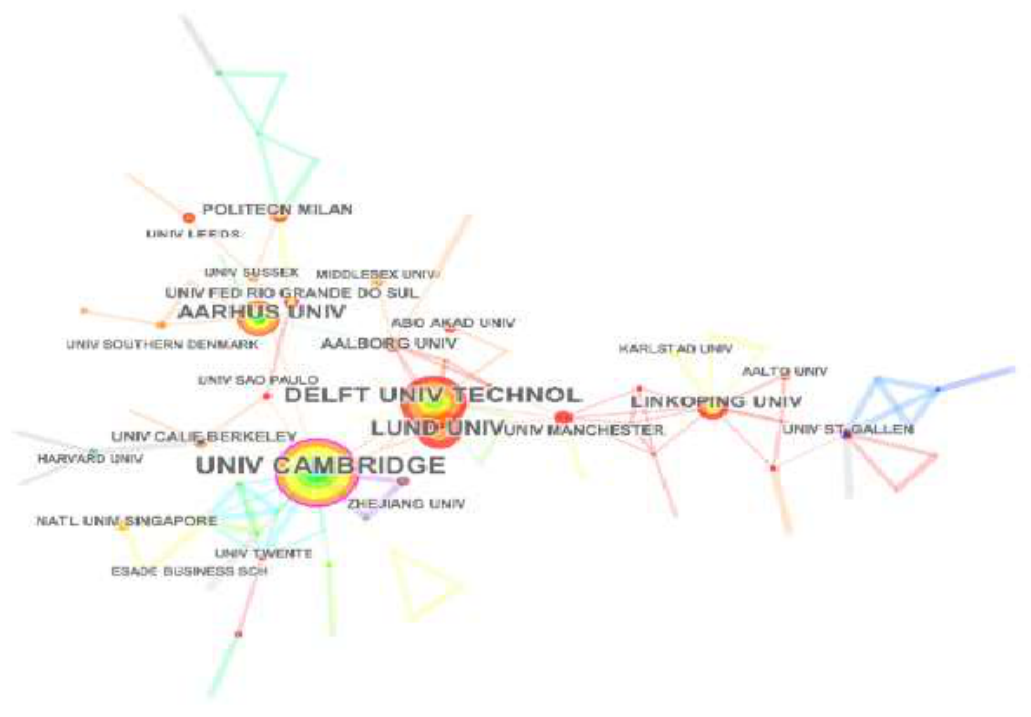

Figure 2 Institutional Collaboration Mapping 


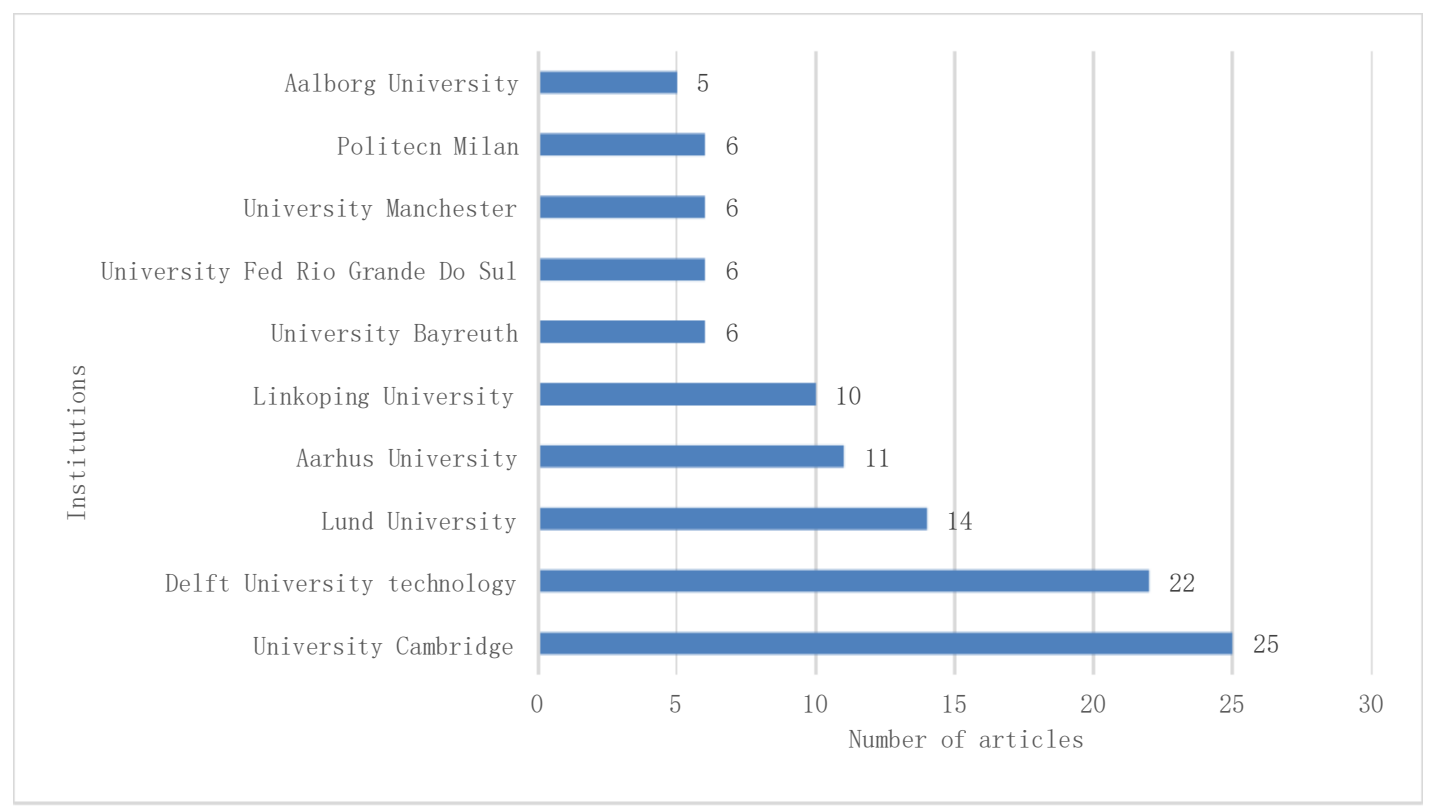

Figure 3 Distribution of Research Institutions

\subsection{Research Trend Analysis}

We conducted an overall time series analysis of 600 articles in the field of business model innovation (as shown in Figure 4) to get an overall picture of the research trends in the field, the level of importance given to it, and other information.

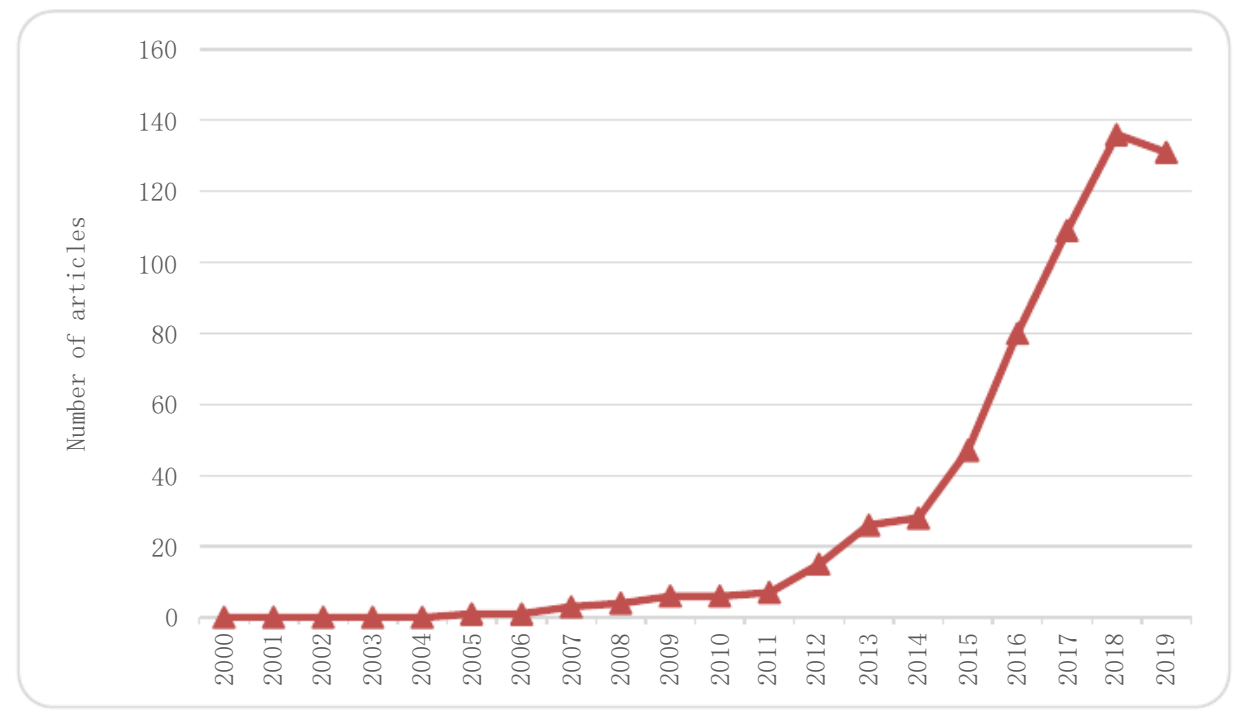

Figure 4 Scatterplot of Annual Number of Issued Articles

On the whole, the number of literature in the field of business model innovation shows an increasing trend year by year, which indicates that business model innovation has received widespread attention from scholars in recent years. The year 2011 can be taken as a research cut-off point, since then, the field has seen rapid growth in research and an almost exponential explosion in the number of publications, which may be due to the increasing number of companies achieving good performance gains through business model innovation. 


\subsection{Keyword Analysis}

We run CiteSpace, set up the keyword analysis, the literature time range is 2000-2019, the Pruning method is Pathfinder, Pruning the merged networks, import the business model innovation literature data in the WOS database, and merge and delete the synonymous keywords, finally get the business model innovation keyword frequency and centrality list (Table 2) and the keyword co-occurrence map (Figure 5). There are 124 nodes, 326 lines, network density of 0.0188 , Q value of $0.7885(>0.3)$, and average profile value of 0.5891 $(>0.5)$ in the co-occurrence map, which indicates that both the co-occurrence map and the cluster map are relatively reasonable.

Table 2 Business Model Innovation Keyword Frequency and Centrality

\begin{tabular}{lcc|lcc}
\hline \multicolumn{1}{c}{ Keywords } & $\begin{array}{c}\text { Freq } \\
\text {. }\end{array}$ & $\begin{array}{c}\text { Centr } \\
\text { ality }\end{array}$ & \multicolumn{1}{c}{ Keywords } & Freq & $\begin{array}{c}\text { Centra } \\
\text { lity }\end{array}$ \\
\hline Business model innovation & 267 & 0.32 & Entrepreneurship & 9 & 0.03 \\
Business model & 141 & 0.61 & Dynamic capability & 8 & 0 \\
innovation & 52 & 0.41 & Case study & 8 & 0.13 \\
Sustainability & 28 & 0.25 & Digitalization & 8 & 0.45 \\
Sustainable business model & 22 & 0.06 & Circular business model & 7 & 0.15 \\
Circular economy & 20 & 0.11 & Sharing economy & 7 & 0 \\
Servitization & 16 & 0.14 & Disruptive innovation & 7 & 0.17 \\
SME & 14 & 0.12 & Digital transformation & 7 & 0.41 \\
Value creation & 13 & 0.67 & Business model design & 7 & 0 \\
Strategy & 11 & 0.43 & Corporate sustainability & 6 & 0.06 \\
China & 10 & 0.12 & Innovation management & 6 & 0.39 \\
Industry 4.0 & 9 & 0.24 & Social innovation & 6 & 0.46 \\
Open innovation & 9 & 0.12 & Value capture & 6 & 0.38 \\
Product-service system & 9 & 0.06 & Service innovation & 6 & 0.1 \\
\hline
\end{tabular}

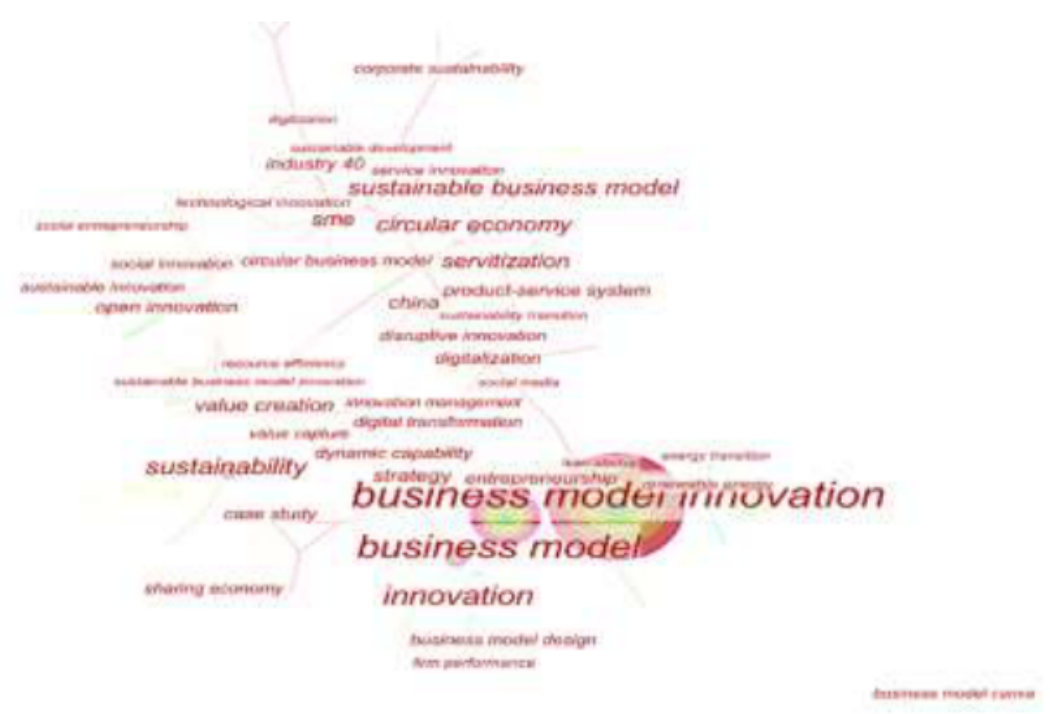

Figure 5 Keywords co-occurrence

By analyzing keywords in the literature, we found the following features.

1) Research on business model innovation is more concerned with the sustainability of the model. Keywords such as "sustainability", "sustainable business model", "corporate sustainability", "dynamic capability" and "strategy" all show that scholars are more concerned with the sustainability of business model innovation in corporate strategy. 
2) The study focuses more on servitization, as reflected in keywords such as "servitization" and "product-service system", arguing that traditional product-first strategies may require servitization innovation to drive overall enterprise model innovation.

3) In terms of research targets, more attention is paid to the model innovation and value creation of SMEs and startups, as reflected by keywords such as "small and medium enterprises (SMEs)", "entrepreneurship" and "disruptive innovation.

4) In terms of research methods, case studies are highlighted, with "case study" and "grounded theory" belong to the high-frequency keywords in this area, indicating that scholars are more likely to adopt the case study approach in the study of business model innovation.

5) From the research content, there is a general focus on value creation, which is the most important aspect of the concept of business model innovation. From the literature, it is clear that the purpose of innovation, whether from a strategic, elemental, or systems perspective, is to be able to increase the value of the firm, which is also reflected in the bibliometric analysis.

6) The focus of the business model design is also based on the characteristics of the business model concept itself. How to design a more competitive business model that can gain sustainable competitive advantage is a common concern of scholars and practitioners alike.

7) Emphasis the concept of the sharing economy, and the important role of the sharing economy in shaping the environment and shaping the model in business model innovation.

To have a more in-depth understanding of all the keywords, based on the keyword cooccurrence analysis, keyword terms are extracted by the LLR algorithm for clustering analysis based on the keyword similarity. As shown in Figure 6, there are 11 main clusters in the business model innovation study, and the main clusters are shown in Table 3. According to the rule of cluster numbering, the smaller the number, the larger the cluster size.

Table 3 Keyword cluster analysis

\begin{tabular}{c|l}
\hline Cluster & \multicolumn{1}{|c}{ Keywords } \\
\hline$\# 0$ & Case study \\
$\# 1$ & Multiple case study \\
$\# 2$ & Value proposition \\
$\# 3$ & Social entrepreneurship \\
$\# 4$ & Sustainable business models \\
$\# 5$ & Digitalization \\
$\# 6$ & Sustainable business \\
$\# 7$ & Value creation \\
$\# 8$ & Service innovation \\
$\# 9$ & Business model innovation (BMI) \\
$\# 10$ & Renewable energy \\
$\# 11$ & Dynamic capabilities \\
\hline
\end{tabular}

According to the clustering themes in Table 3 and Figure 6, scholars generally focus on "value creation" which is one of the most important types of explanations of the concept of business model innovation.

1) According to the literature on business model innovation, scholars mostly use a single case study or multiple case study, which means that this is a common research method used by scholars in the field of business model innovation in the past and has produced a large number of research results ${ }^{[10][11]}$. Cluster $\# 0$ (case study) and cluster \#1 (multiple case study) contain the keywords "firm performance", "ambidexterity", "innovation management" etc., all illustrate this point. 


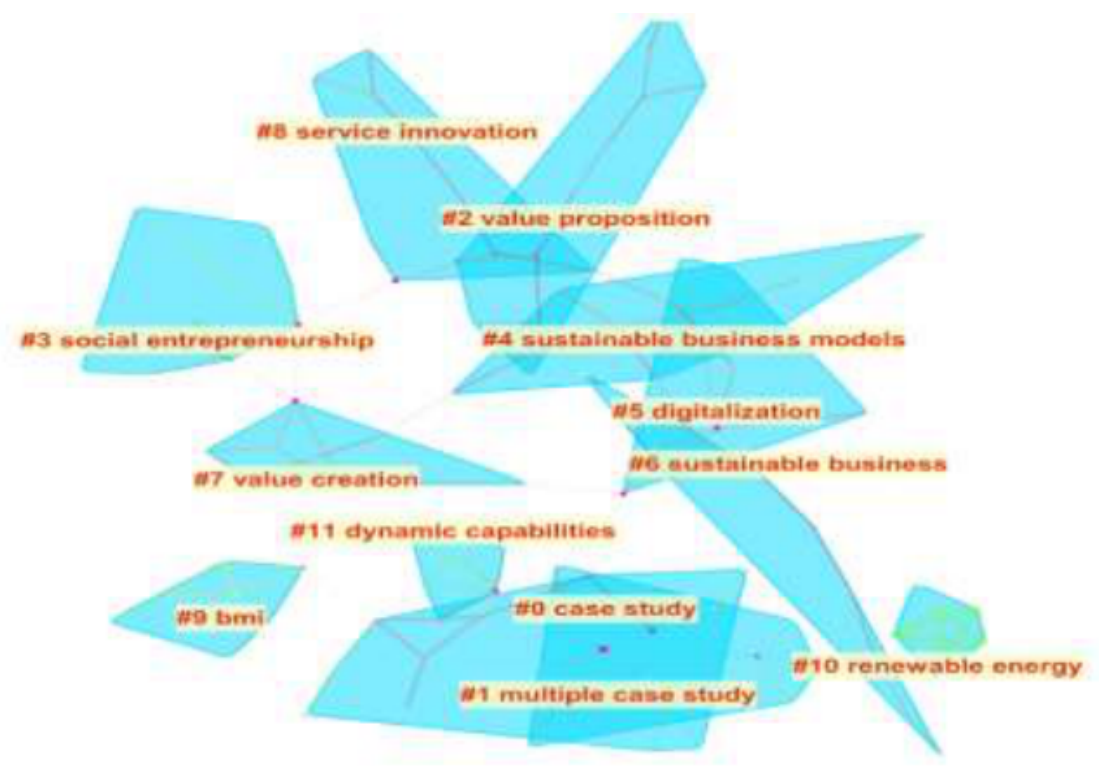

Figure 6 Keyword Cluster

2) Scholars generally agree that the core content of a business model is the value proposition of an enterprise. Enterprises clarify the most important core elements through their value propositions, allocate resources around the core elements, build the business model, and then rationally design the other elements of the business model ${ }^{[12]}$. The $\# 2$ clustering (value proposition) includes the keywords "incumbent", "value proposition", and "value proposition", "produce-service system", etc., are all studied around this clustering theme.

3) Scholars generally focus on the dynamic capabilities of enterprises in uncertain environments $^{[13]}$, and business model innovation and the sustainability of enterprise operations as important considerations for the creation of strategic advantages and the promotion of sustainable operations by focusing on the sustainability of model innovation ${ }^{[14]}$. Cluster \#4 (sustainable business models) contains the keywords "sustainable value creation", "sustainable business models", "circular supply chain", "circular business model", "sustainable value analysis tool", and "process innovation" etc.

\subsection{Research Frontier Analysis}

The research frontier is a subject that is most advanced and worthy of research. Based on the above clustering diagram, CiteSpace software was used to analyze the time line and time zone diagrams of keywords in literature. As shown in Figures 7 and 8 below, respectively, this view allows us to clearly see how the research hotspots in the field of business model innovation research have changed over time.

Scholars' research on business model innovation has recently focused on "open innovation", " circular economy", "product-service system", "industry 4.0", "sustainability", "sustainable business model" and other key aspects, we try to decipher the business model innovation pathway, and make the existing incumbent enterprises, through open innovation and other means, to be able to develop a sustainable business model. To achieve sustainable and effective business operations. 


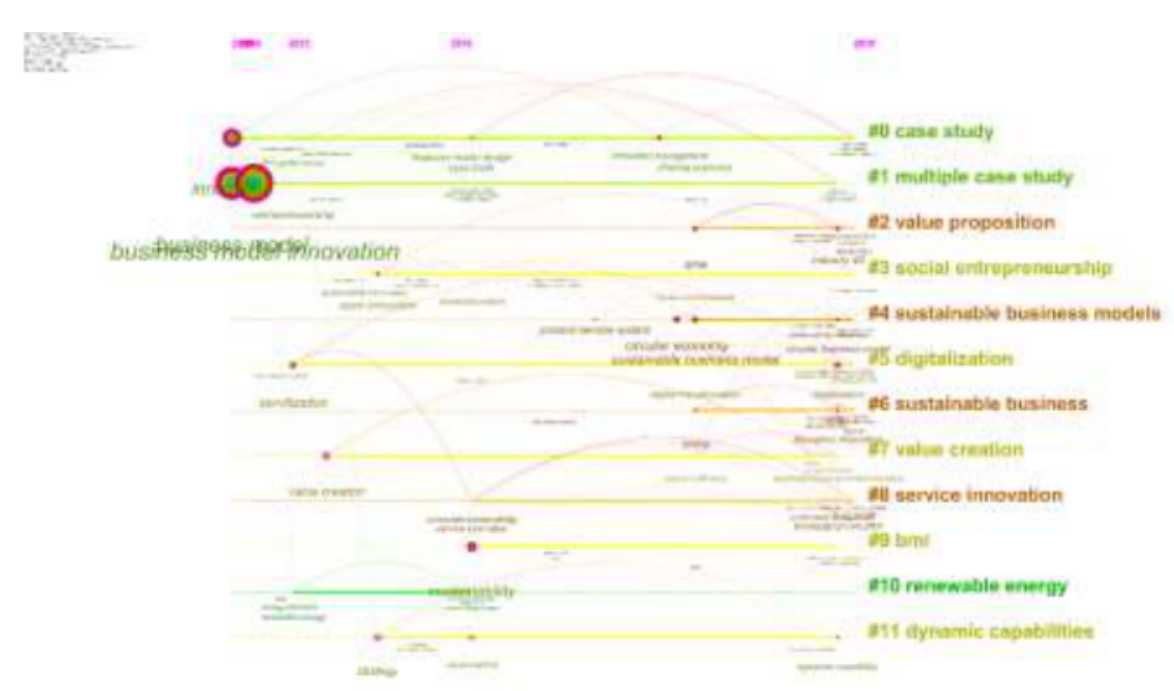

Figure 7 Keyword time line diagram

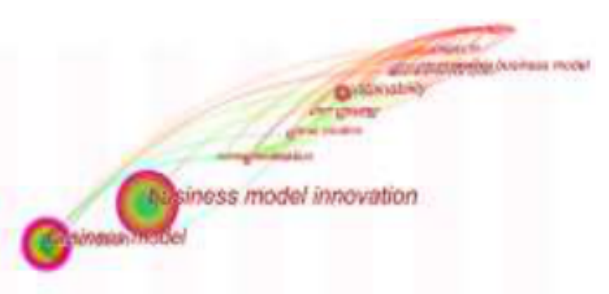

Figure 8 Keyword time zone diagram

\section{CONCLUSION}

This article adopts bibliometric methods and scientific knowledge mapping software, based on the literature data of the WOS database, to analyze the literature on the topic of business model innovation from 2000 to 2019 , and conducts a visualization study to explore the current status, hotspots, and trends of the research in this field. It is found that the number of articles published on the topic of business model innovation has increased year by year from less than 10 articles per year in the beginning to nearly 140 articles in 2019 . Especially after 2011, there has been significant explosive growth in the number of publications in this field, but the overall number is still relatively low, and there is a lot of space for improvement in the future.

1) From the research field, according to the discipline analysis of the source data, it is found that business economics, business administration, and other disciplines are important discipline fields for business model innovation research, gathering more research scholars and producing rich results, accounting for more than $50 \%$ of the overall number of publications, which has a great deal to do with the business model and the conceptual scope of business model innovation, resource allocation and value creation issues at the enterprise level. At the 
same time, research is more focused on science and technology, such as environmental technology, green and sustainable technology, etc., besides the scope of economic management. Also, the collaboration between research institutions in this field is evident and characterized by extensive collaboration on a transnational scale.

2) From the perspective of research hotspots, it is common to focus on the theme of "value creation", which is also the most important significance of business model innovation and the basis of evaluation. Also, the research focuses more on the sustainability of business models, servitization, the innovation of SME, and entrepreneurial models. Case study, multiple case study, value proposition, and sustainable business model are more important research clusters. Also, for the future competition of enterprises, the research focuses on the competitiveness of enterprises from the perspective of sustainable business model innovation and the shaping of long-term value.

3) In terms of research trends, through the analysis of keywords in the literature, such as time line and time zone diagrams, research focuses more on key aspects such as open innovation, circular economy, product-service system, Industry 4.0, sustainability, and sustainable business models. From the above, we can see that scholars in the field of business model innovation have further focused on the traditional industries to achieve sustainable operation and transformation and upgrading through disruptive innovation.

In the past 20 years, the research in the field of business model innovation has made great progress and achieved plenty of results, I find that scholars should focus on the following three points in their future research. Firstly, to break through existing research fields, strengthen interdisciplinary cooperation, and conduct interdisciplinary research on business model innovation; secondly, to focus on the field of sustainable business model innovation, as future competition requires the craftsmanship spirit of continuous innovation, and the focus should be on sustainable business model innovation methods and paths; thirdly, to focus on research based on the continuous development of existing empirical research methods such as case studies. The scholars will put it into theoretical construction, study the internal mechanism and interrelationships of business model innovation, and propose a suitable local theoretical system to guide enterprises to continuously innovate and improve their competitiveness.

\section{REFERENCES}

[1] Gong Limin, Wei Jiang, Dong Yi et al. Research Streams of Business Model: A Citation Analysis of SSCI, 1997-2010 [J].Management Review, 2013,25(6): 131-140.(In Chinese)

[2] Matthyssens P, Vandenbempt K, Berghman L. Value innovation in business markets: Breaking the industry recipe[J].Industrial marketing management, 2006,35(6): 751-761.

[3] Osterwalder A, Pigneur Y, Tucci C L. Clarifying business models: Origins, present, and future of the concept [J].Communications of the Association for Information Systems, 2005, 15(1): 143.

[4] Foss N J, Saebi T. Fifteen years of research on business model innovation: How far have we come, and where should we go?[J].Journal of Management, 2017,43(1): 200-227.

[5] Zott C, Amit R. Business model design: an activity system perspective[J].Long range planning, 2010,43(2-3): 216-226.

[6] Velu C.Business model innovation and third-party alliance on the survival of new firms[J].Technovation, 2015, 35: 1-11.

[7] Dubosson-Torbay M, Osterwalder A, Pigneur Y. E-business model design, classification, and measurements[J].Thunderbird International Business Review, 2002,44(1): 5-23. 
[8] Chesbrough H. Business Model Innovation: Opportunities and Barriers [J] .Long Range Planning, 2010, 43( 2-3): 354-363.

[9] Chen C. CiteSpace II: Detecting and visualizing emerging trends and transient patterns in scientific literature.[J] Journal of the American Society for Information Science and Technology 2006,57(3): 359-377.

[10] Chesbrough H, Rosenbloom R S. "The role of the business model in capturing value from innovation: evidence from Xerox Corporation's technology spin-off companies". [J]. Industrial and Corporate Change.2012,11(3):529-555.

[11] Casadesus-Masanell, Ramon, and Feng Zhu."Business Model Innovation and Competitive Imitation: The Case of Sponsor-Based Business Models."[J].Strategic Management Journal. 2013,34(4): 464-482.

[12] Osterwalder A. "The business model ontology: A proposition in a design science approach". [D].Universitéde Lausanne, 2004, pp.47-58.

[13] Teece D J.“Business models and dynamic capabilities”.[J].Long range planning. 2018,51:4049.

[14] Evans S, Vladimirova D, Holgado M, et al." Business Model Innovation for Sustainability: Towards a Unified Perspective for Creation of Sustainable Business Models".[J].Business Strategy and the Environment, 2017,26(5):597-608. 